\section{International Scientific Journal Theoretical \& Applied Science}

\author{
p-ISSN: 2308-4944 (print) e-ISSN: 2409-0085 (online) \\ Year: $2016 \quad$ Issue: 5 Volume: 37 \\ Published: $30.05 .2016 \quad \underline{\text { http://T-Science.org }}$
}

Eugene Vasil'evna Vinogradova Associate Professor, Candidate of Philosophycal Science, Assistant professor Department of History and Philosophy,

State Maritime University Admiral Ushakov, Russia, grape3@yandex.ru

SECTION 30. Philosophy

\title{
M. A. BAKUNIN'S IDEAS AND PRESENT (TO THE 130 ANNIVERSARY FROM THE DATE OF BAKUNIN'S DEATH)
}

\begin{abstract}
In article Bakunin's ideas opening his negative relation to the power, to the state in general which resist to the personality because any state is body of violence of one over others are considered. A keynote of creativity of Bakunin is the appeal respect for the person, for his advantage and freedom. Now new vision and new positive sense of why denial by Bakunin of the centralized power is connected at him with the statement of freedom of the person, "the external coercion taken from fetters" opens.

Key words: statehood, anarchism, freedom, morality, civil society, domination, responsibility of the power to society.

Language: Russian

Citation: Vinogradova EV (2016) M. A. BAKUNIN'S IDEAS AND PRESENT (TO THE 130 ANNIVERSARY FROM THE DATE OF BAKUNIN'S DEATH). ISJ Theoretical \& Applied Science, 05 (37): $92-$ 98.

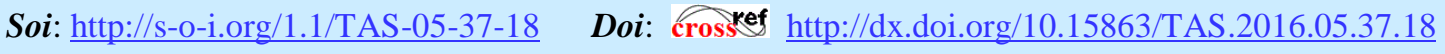

\section{УДК 94(47).084.8}

\section{ИДЕИ М. А. БАКУНИНА И СОВРЕМЕННОСТЬ (К 130-ЛЕТИЮ СО ДНЯ СМЕРТИ БАКУНИНА)}

Аннотация: В статье рассматриваются идеи Бакунина, раскрывающие его отрицательное отношение к власти, к государству вообще, которые противостоят личности, ибо всякое государство есть орган насилия одних над другими. Лейтмотивом творчества Бакунина является призыв уважении к человеку, к его достоинству и свободе. В настоящее время открывается новое видение и новый позитивный смысл того, почему отрицание Бакуниным иентрализованной власти связано у него с утверждением свободы человека, «извлеченного из оков внешнего принуждения».
\end{abstract}

Ключевые слова: государственность, анархизм, свобода, нравственность, гражданское общество, господство, ответственность власти перед обществом.

Среди известных, ярких некогда имен русской философской мысли ныне несправедливо преданных забвению, назовем имя Михаила Александровича Бакунина (1814-1876). В 2014 году отмечалась (весьма скромно) дата 200-летия со дня рождения этого совсем неординарного человека, общественного деятеля, которым восхищались во всем мире. А в 2016 году исполняется 130 лет со дня его смерти, т. е. самое время вспомнить о нем и обратиться к творчеству M. А. Бакунина и как-бы восстановить прерванную связь времен и «навести мосты» наладить диалог с нашей русской философской традицией без издержек, искажений и упрощений рассмотреть идеи одного из классиков русской философской мысли, тем более, что поводов для обращения к творчеству М. А. Бакунина более чем достаточно, ибо даже оценка его места в ряду блестящих философов XIX-XX вв. не однозначно оценивается в истории русской философии.

Михаил Александрович Бакунин родился в 1814 году в семье богатого тверского помещика и был воспитан в духе преданности престолу и религии. В 1828-1833 гг. учился в Петербургском военном училище, по окончании которого отправился на военную службу. Но в 1836 г вышел в отставку и поселился в Москве. Там сдружился со Станкевичем, Герценом, Грановским, Белинским и др. В кружке 
Станкевича изучал немецкую классическую философию, знал в совершенстве диалектику и логику Гегеля. В 1840 г поехал на учебу в Берлин. Знакомство с Руге, Вейтлингом, Марксом пробудили в Бакунине политические интересы, прежде для него чуждыми. Анализируя экономическое и политическое положение Германии, Бакунин утверждал, что судьба ее должна разрешиться в столкновении двух глобальных партий - консерваторов и демократов, стремящихся к полному уничтожению в стране политического и социального мира. Обществу, человечеству, по Бакунину, следует довериться вечному объективному духу, который только потому разрушает и уничтожает, что он есть неисчерпаемый и вечно творящий источник всякой жизни, «страсть к разрушению есть вместе с тем и творческая страсть» [3]. Этот знаменитый лозунг Бакунина был самым ранним, но уже заметным зачатком его последующего анархизма, выпячивания в гегелевской философии момента отрицания.

После поражения польского восстания в 1863 году Бакунин окончательно переходит на позицию анархизма.

Итак, как с позиции сегодняшнего дня определить роль и место философа в истории русской мысли. Возьмем, к примеру, статью о Бакунине в Философском словаре под редакцией И. Т. Фролова за 1983 г. В нем написано, что «М. А. Бакунин - мелкобуржуазный революционер, идеолог анархизма и народничества». И как-бы следуя за марксисткой критикой анархизма, подчеркивается, что за разногласия со взглядами Маркса и Энгельса, Бакунин был исключен из I Интернационала в 1872 году. [18] Как-то очень, действительно, мелко для многогранного творчества и бурной общественно-политической деятельности М. А. Бакунина. А что уж говорить о публицистической оценке анархизма как чисто «отрицательного явления», как символа разрушения, ниспровержения всех основ, всех и всяческих авторитетов.

Ну, насчет ниспровержения авторитетов, то можно сказать, что новатор новой науки, философ XVII века Френсис Бэкон к этому даже призывал, ибо считал, что вера в авторитеты мешает самим ученым исследовать явления и добиваться достоверного знания.

Но есть и противоположное мнение о Бакунине. Так И. И. Блауберг на Чтениях, посвященных 175-летию со дня рождения М. А. Бакунина назвала его «великим мыслителем и революционером, прошедшим долгий путь идейного развития и ставшего родоначальником философских идей анархизма в нашей стране» [6]

Так кто такой на самом деле Бакунин и в чем смысл анархизма? Почему нам надо установить истину? Автор книги «Бакунин», вышедшей в 1970 году в серии «ЖЗЛ» утверждает, что Бакунин «в большей мере принадлежит будущему, чем своему времени» [15]. Т.е. он нужен нам сегодня, теперь, подчеркивает Н. М. Пирумова, становится все более очевидной современность Бакунина, считавшего себя, кстати, не чистым мыслителем, а «страстным искателем истины и приверженцем свободы», но разве истинный философ не поборник и не страстный искатель истины? И если подойти к творчеству М. Бакунина, П. Кропоткина, Л. Толстова и других приверженцев анархизма, то откроется новое видение и глубокий позитивный смысл того, почему отрицание Бакуниным централизованной власти, государства как такового связано у него со страстным утверждением свободы человека, «извлеченного из оков внешнего принуждения». [15] Поэтому главным лейтмотивом творчества Бакунина является призыв уважения к человеку, к его достоинству и свободе. А эти принципы все сильнее звучат в современной этической философии, призывающей оценивать человека по критериям морали, справедливости и мудрости. [8-C.116]

И дальнейшее исследование современных мировых реалий приводит многих к выводу, что на динамику общественных процессов могут оказывать более значительное влияние не только властное принуждение и властное предписание, которое теперь отнюдь играет далеко не решающую роль. Поэтому, например, Кропоткинское позитивное понимание этики: вполне может совмещаться с сущностью права не как только внешнего регулятора, но и как внутреннего отношения, правда тогда, когда право становится нравственным [11]. При этом следует подчеркнуть, что нравственность здесь выступает как основа права и имеет она множество принципов, таких как слидарность и взаимопомощь, свобода и ответственность.

А ведь эти понятия морали как-то нынче «вышли из моды». Но в начале, да и в середине XX в. в трудах, например, Е. Н. Трубецкого и И. А. Ильина эти категории о моральности права успешно развивались, но, увы, не стали доминантой нашего философского сознания. И прав, на наш взгляд, автор статьи «Идеи П. А. Кропоткина в XXI веке» С. Зарочинцев, который подчеркивает, что на нынешнем этапе развития общества важную роль играет именно философская оценка права, «максимализация нравственности в нем». [11] Тогда, возможно, не было бы такой трагедии на Украине, когда «силовик» убивает без зазрения совести ополченца, а заодно и вовсе безвинных младенцев, их матерей и стариков. Вот именно такой ситуации должна быть дана, прежде всего, 
моральная оценка с позиции морального права, поэтому актуальна сейчас разработка такой правовой теории, которая основана не на западных либеральных и индивидуалистических концепциях, а на парадигме социального, морального обоснования права. Именно с такой морально обоснованной установки, то, что делается на Украине «неприлично, ибо это будет проявлением негуманного, варварского мышления». [14 - С.99] Как известно, Карл Маркс сказал об этом тоже достаточно красноречиво, о том, что «пить нектар из черепов убитых» - это отвратительно, бесчеловечно, противоестественно, однако, это страшные реалии жизни людей XXI века!

Если задать вопрос: кто виноват? То среди ответов на этот вопрос напрашивается такой вывод, что виноваты власти воюющих сторон и тех, кто стоит за их спиной. Кто-то сказал, что сама природа власти толкает ее совершать карательные функции (как внутри страны, так и во внешней политике) и именно там, где гуманнее и справедливее употреблять только контролирующие функции! Уж очень соблазнительно для власти «власть употреблять» даже там, где вообще этого вовсе не требуется. Не надо забывать, что кроме карательных функций у власти есть и другие важные дела и функции.

И идеал правового государства, в котором действует нравственное право вовсе не абстрактный идеал, а анархический.

Идеал, стоящий на защите прав и свобод личности, где осуществляются принципы солидарности и взаимопомощи, свободы и ответственности, в конце-то концов может осуществляться в рамках правового государства, где право нравственного по-сути, как общество свободных людей, во главе которого стоит не безнравственная бюрократия, попирающая права и свободы граждан, а некое объединение людей для достижения справедливых целей, действительно социальное государство, где возможно достижение социальной справедливости. А правовед и общественный деятель Жириновский с пеной у рта доказывал с телеэкрана, что «справедливости нет (здесь он прав), не было (кто знает?) и не будет!» Пока у власти стоят такие правители, как он - точно справедливости не будет! Хотя тот же Жириновский, в последнее время, высказывает иногда и интересные, и даже справедливые мысли. А пока существует такой порядок: закон суров, но далеко не справедлив. Когда есть закон, но отсутствует нормальное правоприменение законов, которое встречается в нашей действительности. Так, старуху 85 лет выдворила из квартиры полиция. Квартиру трижды перепродавали вместе со старушкой, и это сделала ее внучка. И таких случаев в реальной жизни, увы, у нас в России, предостаточно! Как быть?

После крушения СССР, создано капиталистическое государство, где утверждалась такая форма правления как «плутократия» (по классификации Аристотеля), т. е. сращивание олигархического управления с чиновничеством. Куда идет это общество, где правит бал финансовый капитал. Философы предлагают нам встроить в Россию гражданское общество.

В современном обществознании используется так же термин, введенный в научный оборот Гегелем, это термин «гражданское общество», как альтернатива государству. Суть идеи гражданского общества состоит, пишет В. В. Воробьев, в дуализме общества и государства и разъясняет, что такой дуализм характерен для общественнополитической системы, отождествляемый с капитализмом, политической демократией и правовым государством. [9] Важным уточнением к определению гражданского общества является то, что гражданское общество - это «своего рода социальное и социокультурное пространство» в котором люди связаны и взаимодействую друг с другом в качестве независимых друг от друга и от государства индивидов. [9]

Гражданское общество - это арена деятельности, классов, партий, социальных групп, корпораций, сословий, институтов, регулируемых гражданским правом и прямо независимых от государства. В рассматриваемом гражданском обществе, Гегель подметил, что многочисленные составляющие гражданского общества находятся в состоянии конфликта, поэтому неустойчивы и несопоставимы друг с другом. Они, по его мнению скорее напоминают поле боя, где сталкиваются частные интересы и случается, что развитие одних элементов гражданского общества может привести к подавлению других его элементов. Однако истинных причин появления одних и исчезновения других элементов Гегель не раскрыл, это сделали классики марксизма, создав диалектико - материалистическое понимание всемирной истории, разработав учении о развитии и смены общественно - экономических формаций. Он показал, что само государство появляется на определенном этапе развития человеческого общества и по законам диалектики должно исчезнуть с изменением способа производства. Поэтому властные отношения, функции подавления и угнетения одного класса другим не будут существовать вечно. И если властные органы достаточно разумны, то они не должны усиливать свои функции узурпаторства, не делать попыток замены демократических 
принципов управления обществом без усиления властного принуждения в пользу применения контролирующих функций, на основе принципа социальной справедливости. Кроме того, наличие гражданского общества предполагает наличие в нем форм самоорганизации людей, включающую различного рода, добровольно сформировавшихся негосударственных экономических, социальных, профессиональных, образовательных, религиозных, культурных и иных институтов, организаций и союзов.

Главное предназначение гражданского общества состоит, по мнению Воробьева, в достижении консенсуса между различными социальными слоями и интересами. Оно призвано определить нормы и границы, позволяющими противостоять разрушительным последствиям борьбы различных сил и направить это противостояние в созидательное русло, что привело бы к усилению общественного прогресса [9]. Важнейшими институтами гражданского общества являются: семья, школа, церковь, общности соседей и друзей, а также другие добровольные организации, такие как, например, в советском обществе пионерия и комсомол, партии, профсоюзы, которые могут заставить индивида соблюдать общепринятые нравственные нормы. Именно они (эти организации и союзы) способны играть очень важную, в частности, воспитательную роль. Государство не способно выполнять эти функции и прибегает к ним лишь в том случае, если эти институты гражданского общества сами не в состоянии справиться с ними. С. Л. Франк определяет гражданское общество как некую молекулярную общественную связь, изнутри сцепляющую отдельные элементы в свободное и пластически гибкое целое. Но самая главная роль гражданского общества, со слов В. В. Воробьева, состоит в том, что это высокоразвитая общность людей, обладающая суверенным правом на жизнедеятельность: это самоуправляющаяся общность, которая может и способна осуществлять контроль над государством [9].

И что еще важно для развития гражданского общества в России, так это то, что эта общность способная к самоуправлению и справедливости, которая может оказывать свое серьезное воздействие на государственные органы к соблюдению этой справедливости.

Но есть и другая точка зрения подхода к функционированию гражданского общества, когда в Конституции государства есть очень важное обстоятельство. В статье «С чего надо строить гражданское общество?» д. ф. н. Перуанского С. С. поднимается вопрос о том, что строительство и существование самого гражданского общества зависит от Конституции России, где нечетко сформулированы основополагающие положения, определяющие действия всего общества. «Казалось бы, - пишет Перуанский, - государственная идеология - это проблема государства, а не гражданского общества, но последнее должно быть построено в государстве, а не в каком-то абстрактном пространстве» [16]. Более того, важно подчеркнуть, что ядром государственной идеологии являются принципы организации политико - экономического процесса. Перуанский подмечает, что статьи Конституции №7 и №13 противоречат друг другу. Статья №7 Конституции говорит о том, что РФ - социальное государство, и это ключевое положение государственной идеологии. А статья №13 «дезавуирует» статью №7, так и всю Конституцию, т. к. означает, что у него нет никакой обязанности для идеологии. Это, более того, означает, что у него нет никаких ценностных ориентиров и нравственных ограничений. Такому государству, с позиции Достоевского, «все дозволено». И далее, Перуанский подчеркивает, что можно ли построить гражданское общество в условиях «официально заявленной вседозволенности, предоставленной государственной машине!»[16] А для построения гражданского общества в стране нужна гуманистическая идеология, которой, увы, нет!

Итак, для устранения гражданского общества надо первым делом устранить «демагогическую плутократическую статью Конституции» [13 - С.111]. А ведь об этой статье Конституции уже не раз говорилось! А как ловко укрывались под этой статьей №13 некоторые политики! И как подействует на них разоблачение Перуанского и других?

Но как в настоящее время философия определяет свое отношение к современному миру, и как она понимает современное мироощущение и мирочувствование? Оно, по мнению многих философов, кощунственно. Само моральное сознание, замечают они, пока еще както присутствует в современной культуре, но современный подход к культурным ценностям, к нормам культуры, является легкомысленным, поэтому не требует ни особого таланта, ни усилий, ни вложения средств, ни умения, а поэтому легко и просто укладывается в обыденные рамки какой-то упрощенности, граничащей с пошлостью. Но это уже тогда понимал Пушкин, когда писал об Онегине, о его жизненной позиции, позволяющей ему при решении важнейших общественных проблем «коснуться до всего слегка с ученым видом знатока», а Герцен назвал такую позицию в науке «дилетантизмом». Особенно досадно, более того, недопустимо такое отношение к делу чиновников во власти. Как пишет В. М. Артемов, идеал, в 
первую очередь, «предполагает прочнейшие нравственные основания совместной жизни, а также свободу, оборотной стороной которой выступает ответственность» [1]. Но для утверждения такого идеала необходим творческий подход, творческое видение мира на основе осознания «преимуществ ответственного самоуправления» [1] Но слово «ответственность», для многих чиновников слово, которое они не хотят признавать, ибо как по этому поводу сказал Ф. Тютчев, что в мире существует парадокс: чем больше власти, тем меньше ответственности, а по мнению А. Терещенко, «ответственность власти в полной мере не реализована еще нигде в мире»[1]. И как теперь открыто пишут в печати и говорят по телевидению, что нынешняя власть не владеет ситуацией и брать на себя ответственность за происходящее в стране не хотят, т. к. сосредоточивают усилия только на том, чтобы «удержаться на своих постах».

Но существует логика исторического развития общества, которую вскрыл еще $\Phi$. Гегель. Он подчеркивает, что правительство, которое провозглашает, что оно есть осуществление всеобщей воли или всеобщей свободы, в действительности «не может проявить себя иначе, как в виде некоторой партии (Faktion)» [10], при этом оно устанавливает такой порядок, с которым только под страхом смерти или ужаса мирится индивидуальное сознание». [10] Поэтому, хорошо прочувствовавший на своей собственной шкуре Бакунин подчеркивает, что свобода и государство несовместимы. Она возможна только при социализме. И далее он поясняет: «Свобода без социализма - это привилегия, несправедливость. Социализм без свободы - это рабство и животное состояние». [2]

Т. к. государство у Бакунина не совместимо со свободой, оно несовместимо и с государственным социализмом. Поэтому Бакунин выступает за безусловное уничтожение государства и государственного социализма Лассаля, Маркса и др. Единственно, что может сделать государство - это уничтожить наследственное право, закрепляющее экономическое, политическое и социальное неравенство.

На месте государства, по Бакунину, должна возникнуть свободная федерация снизу вверх индивидов и производительных ассоциаций (товариществ, общин), областей и народов, с сохранением для всех возможности объединяться и выходить из объединения. По мнению Бакунина, дни государства сочтены, но государства сами не валятся. Поэтому, говорит он, нужна революция. Но освобождению русского народа препятствует патриархальность, общинность, вера в царя. «Вот почему разбой составляет важное историческое явление в России. Первые бунтовщики были Разин и Пугачев - разбойники. А рабочий класс должен быть «организатором народной революции»[2].

И эти слова, и эти идеи были восприняты значительной частью русской интеллигенции, составившей одно из направлений народничества.

Почему же Бакунин сотрудничая какое-то время с Марксом в вопросе о сущности государства расходится с ним? Потому, что сидевший в застенках российских и иностранных тюрем, Бакунин особенно ценил свободу. Свобода для него - это высшая цель человечества и его развития. И так как государство, по Бакунину, несовместимо со свободой, оно несовместимо тогда и с социализмом, поэтому Бакунин выступает за безусловное уничтожение государства и государственного социализма Лассаля, К. Маркса, К. Либкнехта и др.

Бакунин утверждает, что государство создано не природой, не Богом, не общественным договором, а «сговором эксплуататоров». «Государство - это самое вопиющее, циничное и полное отрицание человечности. По Бакунину оно разрывает всеобщую солидарность людей на Земле и объединяет только часть их с целью уничтожения (сейчас это с особой силой демонстрируется на Украине), завоевания и порабощения всех остальных, где начинается государство, кончается «индивидуальная свобода» и наоборот».

А расхождение Бакунина с Марксом произошло после того, как Марксом была выдвинута идея о том, что на первом этапе развития общества после победы пролетариата (социалистической революции) должна возникнуть новая власть - власть рабочих, названная им «диктатурой пролетариата», как переходная форма государства с дальнейшим его отмиранием.

Бакунин же считает, что после свершения социалистической революции государство должно быть отменено.

Но учение Маркса в то же время не отрицает уверенность Маркса, что отмирание государства должно произойти со временем упрочнения пролетарской власти, где функция насилия сохраняется до тех пор, пока имеется сила, сопротивляющаяся укреплению народовластия [12]. И в то же время Маркс утверждал, что новое государство - это новая демократия, гарантирующая самые широкие права и защищающая интересы трудящихся, готовая дать решительный отпор тем, кто поднимает руку на завоевание народа, мешает упрочению социалистического способа производства [12]. При этом Маркс подчеркивает, что управлять 
новым обществом - дело народа, организованного в коммуны, что суть новой власти - это «управление народом посредством самого народа» [12].

И здесь нет противоречия с тем, что утверждает М. Бакунин, ибо идея Маркса состоит в том, что народ в условиях строительства социализма и коммунизма не знает над собой иной власти, кроме власти собственного объединения [13].

Тюрьмы и угроза смертной казни не сломили Михаила Александровича Бакунина, и его имя вписано золотыми буквами в историю России. Всю свою жизнь воевал он с государственной несправедливостью и призывал к борьбе за свободу человека, человеческой личности. И не надо думать, что круг этих людей, исповедующих это мировоззрение мал. По словам Бердяева в работе «Русская идея», он подчеркнул, что анархическая позиция вообще очень характерна для сознания и поведения русского народа, а Бакунин в особо отчетливой форме выразил эту позицию. И еще Бердяев делает различия между анархией, стремящейся к разрушению, несущему за собой хаос, и анархизмом, как идеалом свободной гармонии и лада. Да и сам Бердяев исповедовал идеи анархизма в его именно созидательном плане. Он писал, что «у меня было ранее сознание того, что мир, общество, цивилизация основаны на неправде и зле...» [7 - C.114] И поэтому он всегда защищал «принцип духовной ценности... принцип личности как высшей ценности, ее независимости от общества, государства, от внешней среды» [7 - С.242]. И сам признался в том, что ему «метафизически присуща анархическая, персоналистически-анархическая тенденция...» и, что священно, по его мнению, не общество, не государство, не нация, а человек. [7 - C.114]. Так что анархизм - идея, захватившая, можно сказать, целое столетие, и теперь вновь становящаяся актуальной в XXI веке, когда с очевидностью человечество ощущает, что современная цивилизация, ее ценности, утратили свою значимость, пришли в тупик. Надлежит новый поворот, от техногенной цивилизации, где, как говорил Бердяев, «гибнет человек» к новым подходам и идеям, которые являются альтернативой централизации власти - к идеям децентрализации, административной системе - к самоуправлению, а также идею марксизма о диктатуре пролетариата к ее замене - по
Бакунину на безгосударственный коммунизм, иначе общественная собственность станет собственностью чиновников, что и произошло в CCCP.

Таким образом, философские установки Бакунина определили его социальнополитические и экономические взгляды. И поэтому особенно важно понять, что его революционная позиция не была легковесной, она не сводилась к чистому отрицанию, а имела серьезное философское обоснование. Его философские работы полны философских размышлений о мире и человеке. Как сторонник органического мировоззрения, он говорит о гармоническом балансе человечества и природы. Бакунин отмечает, что не может человек ни победить, ни обуздать природы, ибо свобода немыслима без строгого применения законов природы, в том числе закона солидарности и взаимопомощи. И поэтому Бакунин считал, что развитие централизованного аппарата власти нарушает гармонию Вселенной. Поэтому эта власть противостоит самоуправлению и федерализму. Таким образом, централизации власти он противопоставляет децентрализацию, административной системе - самоуправление [2].

И возражая классикам марксизма по проблемам теории социализма доказывал, что при определенных условиях возможно перерождение диктатуры пролетариата в авторитарный государственный коммунизм, где общественная собственность на средства производства станет собственностью чиновников. И поэтому, с его точки зрения, пролетариат должен быть союзником крестьянства и его не надо подавлять диктатурой. Бакунин считал, что диктатура пролетариата неосуществима на деле, т. к. она неизбежно превратится в диктатуру пролетарских чиновников, что и было «красной бюрократией». Уже предвидя опасность тоталитаризма при сосредоточении властных функций в одних руках, Бакунин предусматривал и возможность появления «диктатораимператора». Но в тоже время, Бакунин верил, что будет время, «когда на развалинах политических государств оснуется совершенно свободно и организуя снизу вверх, вольный братский союз вольных производительных ассоциаций, общин и областных федераций, обнимающих безразлично, потому что свободно людей всех языков и народностей. [2]

\section{References:}

1. Artemov V (2007) Freedom and morality. Moscow, "Rehabilitation", 2007.
2. Bakunin MA (1989) Statism and Anarchy. Moscow, 1989., pp.387. 


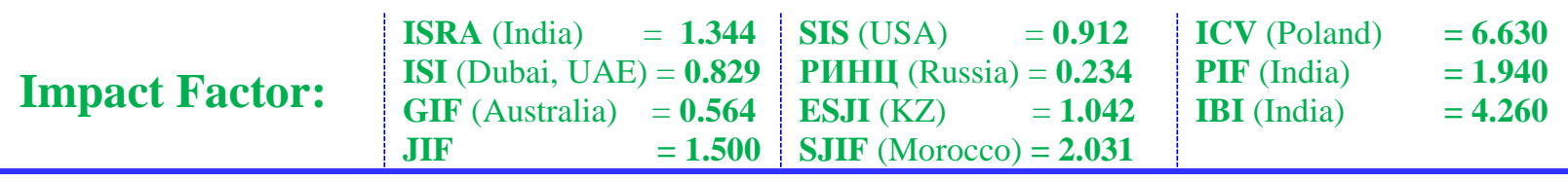

3. Bakunin MA (1917) God and the State // Full. cit. cit .. - St. Petersburg 1917

4. Bakunin MA (1986) international secret society of the liberation of mankind // Get up, man. M., 1986, pp. 255

5. Bakunin MA (1989) Philosophy. Sociology. Policy. - M., 1989.

6. (1990) Blauberg II Anarchism. What we know about him? // Problems of Philosophy, 1990, №3, pp.160

7. Berdyaev NA (1990) Self-knowledge. Moscow.

8. Belkin GL, Frolova M (2014) Problems of improving the human // Vestnik RFO, №4, 2014., pp 32-36

9. Vorobiev VV (2011) State and civil society: the interdependence and separateness // Coll. scientific. works, issue №16 h. 2, Novorossiysk 2011.

10. Hegel GV (2016) - Op, T. 4, p.318.
11. S. Zarochintsev (2014) Ideas PA Kropotkin in the XXI century. // Bulletin of RFO, №14, 2014, pp 24-25.

12. (2016) K. Marx and F. Engels. ed. II of, T. 25, Part 2 -. P. 250

13. (2016) K. Marx and F. Engels, Soch., T.17, pp. 344,350 .

14. Myasnikov AT (2015) decaying society needs cleansing war? Philosophical - journalistic criticism of modern war apology // Vestnik RFO, number 1, 2015, pp. 98

15. Pirumova IM (1970) Bakunin, M., ZHZL, 1970.

16. Peruvian SS (2015) Where to start to build a civil society? // Bulletin of RFO, number 1, 2015, p.109.

17. Tereschenko A (2015) Ruins incompetence. // Ed. house. "Arguments of the Week" 2015

18. (1981) Dictionary of Philosophy // Under. Ed. Frolov, Moscow, 1981. 